\title{
O SIGNIFICADO DA INVESTIGAÇÃO SOBRE OS AFRICANOS ESCAPADOS DE NAVIOS NEGREIROS NO SÉCULO XIX*
}

\author{
The Significance of Africans who Escaped from \\ Transatlantic Slave Ships in the Nineteenth Century
}

David Eltis $^{* *}$

\begin{abstract}
RESUMO
Versão integral de conferência proferida no IV Encontro Escravidão \& Liberdade no Brasil Meridional, Curitiba, maio de 2009.

Palavras-chave: escravidão; tráfico de escravos; africanos livres.
\end{abstract}

\begin{abstract}
Full version of Keynote Address delivered at the IV Encontro Escravidão \& Liberdade no Brasil Meridional, Curitiba, May 2009.
\end{abstract}

Key-words: slavery; slave trade; Africans escaped from slave ships.

Parece presentemente que o tráfico de escravos atlântico carreou da África 12,5 milhões de cativos, tendo distribuído os 10,7 milhões que sobreviveram à travessia por regiões das Américas espalhadas desde o Norte temperado (Nova Inglaterra) até o Sul temperado (Rio da Prata) ${ }^{1}$. Até 1820, eles superaram em número os migrantes partidos da Europa segundo uma razão de, no mínimo, três para um. Não menos que $45 \%$ desse total foi levado apenas para o Brasil e, tendo o tráfico persistido por quase quatro séculos, um em cada três dos escravos desembarcou durante seus últimos

* Tradução de Carlos A. M. Lima.

** Emory University, Atlanta.

1 Quanto à elaboração dessas estimativas, ver o ensaio introdutório de ELTIS, David; RICHARDSON, David (Org.). Extending the Frontiers: Essays on the New Transatlantic Slave Trade Database. New Haven, 2008, p. 3-68, assim como a página de estimativas de www.slavevoyages.org. Essas fontes incorporam os novos dados descobertos na última década em arquivos situados por todo o mundo atlântico. 
sessenta anos. O Brasil e, em menor extensão, Cuba, são, portanto, as partes da América com os laços mais fortes e mais recentes com a África, mesmo levando em conta o fato de que, desde 1992, chegaram aos Estados Unidos mais africanos que durante toda a época do tráfico de escravos. Mas, como muito dessa migração forçada aconteceu na parte final da época do tráfico de escravos, ela foi conduzida sob circunstâncias de clandestinidade. A ilegalidade trouxe junto a si o risco de sanções, detenção, processos judiciais e, para alguns daqueles que eram mantidos debaixo dos conveses, a libertação. Para muitos dos africanos que enfrentaram o ordálio que começava com a captura por um traficante de escravos, e passava depois pela recaptura por parte de uma autoridade estatal responsável pela supressão do comércio de almas, foi mantido um registro do tipo de informação pessoal que é raro na história da escravidão e do tráfico de escravos que a sustentou. O objetivo deste trabalho é dirigir a atenção de mais historiadores para esses registros e apontar o modo de usá-los.

Apesar da recente enxurrada de interesse pelos africanos que emergiram das embarcações negreiras detidas para adquirir um novo estatuto durante o século XIX, os estudiosos ainda precisam atentar para todo o potencial do estudo dos africanos livres como um grupo ${ }^{2}$. Estabeleçamos

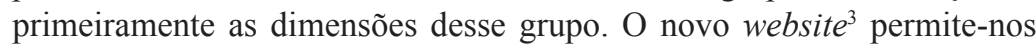
localizar os cativos detidos na rota para a América e então adjudicados. Entre 1808 e 1865, cerca de 177.000 indivíduos foram desembarcados e redirecionados depois de a embarcação na qual eram mantidos ter sido detida ${ }^{4}$. Eles compunham um dos maiores ramos da diáspora africana. Superavam em número todos os cativos levados, durante todo o período do tráfico de escravos, diretamente da África para Chesapeake, ou para o Caribe holandês, ou ainda para a Amazônia. Se somarmos ao seu número

2 As exceções mais importantes são MAMIGONIAN, Beatriz. To be a liberated African in Brazil: labour and citizenship in the nineteenth century. PhD Dissertation, University of Waterloo, 2002, bem como uma coletânea de ensaios de publicação próxima, The Human Tradition in the Black Atlantic 1500-2000, editada juntamente com Karen Racine. Ver também ADDERLEY, Roseanne Marion. "New negroes from Africa": Slave Trade, Abolition and Free African Settlement in the Nineteenth-century Caribbean. Bloomington: Indiana, 2006.

$3 \mathrm{O}$ autor se refere a www.slavevoyages.org (N. do T.).

4 A fim de isolar este grupo, dirigir-se a www.slavevoyages.org e colar na url http://slavevoyages.org/tast/database/search.faces?yearFrom=1809\&yearTo=1866\&fate=11.1 9.23.51.102.103.104. 106.108.109.110.111.112.113.114.118.120.121.124.125.126.127.128.130.132.134.135.138.141.144.148. 161.164.165.166.201 
o dos escravos que se revoltaram durante a travessia e que se safaram de posterior reescravização, ele pode ter se aproximado do de todos os cativos desembarcados nas Américas por navios norte-americanos antes de $1808^{5}$. Mas, mais importante, esse ramo específico da diáspora deixou atrás de si, no registro histórico, pegadas maiores que as de qualquer outro. Sabemos mais sobre os indivíduos arrancados dessas viagens de tráfico interrompidas que sobre os vendidos como escravos nas Américas. Também sabemos muito mais sobre suas vidas subsequentes e sobre as comunidades que eles estabeleceram após sua liberação dos navios negreiros.

Os registros que eles deixaram para trás podem ser usados para iluminar o processo de escravização na África, a travessia para as Américas e a criação de novas comunidades afro-americanas, processos que não se aplicavam somente a eles, mas também a todos os 12,5 milhões de africanos escravizados empurrados para o tráfico de escravos transatlântico. Devemos ver nesse grupo os substitutos vitais de milhões de africanos que necessariamente desapareceram na escravidão americana sem deixar qualquer registro de suas vidas. É claro que os que chamamos de "recapturados", tendo evitado esse destino, não tiveram, em sua maioria, que enfrentar a escravidão nas Américas. Assim, o controle que tiveram sobre suas vidas após a libertação do navio negreiro foi muito maior que o dos vendidos para as plantations. A significação cultural deste fato dificilmente pode ser exagerada. O registro deixado por eles deve permitir-nos rastrear as origens africanas dos cativos de um modo que é inviável no caso dos perpetuamente escravizados. E o estudo das comunidades que eles estabeleceram tanto no Velho quanto no Novo Mundo, após suas experiências na travessia atlântica, deve prover a base para que os estudiosos revejam muito do que já foi publicado sobre as consequências culturais do tráfico de escravos (ou, mais especificamente, da crioulização), começando pelo trabalho fundador de Sidney Mintz e Richard Price ${ }^{6}$.

Como exatamente definimos a categoria "africanos liberados"? De onde vieram e para onde foram? Talvez mais importante: qual é seu significado para os estudos da diáspora e para o entendimento sobre o mundo atlântico no século XIX? É mais fácil responder essas perguntas

5 Essas comparações utilizam a página de estimativas de slavevoyages.org e da discussão sobre o contingente e a distribuição do grupo dos africanos livres desenvolvida mais à frente neste mesmo artigo.

6 Ver particularmente o ensaio que será publicado por Richard Price em ELTIS; ENGERMAN (Org.). The Cambridge World History of Slavery, v. 3. 
agora que há duas décadas. Durante a era do abolicionismo, os governos da Inglaterra, de Portugal, da Espanha, da França, dos Estados Unidos e do Haiti autorizaram a interceptação de navios negreiros e a remoção dos cativos que eles continham ao redor do Atlântico e dos litorais das regiões envolvidas no negócio. Significativamente, todas essas nações, com a óbvia exceção do Haiti, tinham sido grandes potências traficantes antes que a abolição deslanchasse. Ao passo que as detenções realizadas por britânicos e norte-americanos estão bem documentadas, aquelas das outras nações são mais difíceis de rastrear. Parece, no entanto, que sobreviveu algum registro de mais de 95\% delas. O website Voyages mostra que, entre 1808 e 1866, navios e autoridades capturaram 1.983 embarcações, ou algo próximo de um quarto do total de 8.217 viagens realizadas a partir de 1808 . É claro que muitos desses navios negreiros não tinham nenhum escravo a bordo quando foram capturados - foram detidos antes de embarcar cativos, ou então depois de tê-los desembarcado, com sucesso, nas Américas, e como nesse período o valor de uma embarcação de tráfico provavelmente constituía apenas algo entre cinco e vinte por cento do valor dos escravos que carregava ou estava destinada a carregar, grande parcela dessas perdas não foi muito destrutiva para as pessoas que haviam organizado as viagens ${ }^{7}$. Noventa por cento dessas embarcações capturadas eram de propriedade de residentes dos portos mais importantes do Brasil e de Cuba, e a maioria navegava com bandeira portuguesa ou brasileira no momento da captura.

É possível dizer que apenas 670 das embarcações capturadas tinham realmente escravos a bordo (ou foram pegas pelas autoridades após o desembarque). Isso levanta a debatida questão do destino dos africanos recapturados tirados daquelas embarcações que realmente tinham escravos. Em que medida estavam realmente libertados os recapturados, tendo em vista que iam parar nas mãos do sistema judicial de uma região na qual a escravidão de plantation ainda estava em rápida expansão? Excluí os recapturados entregues aos governos do Caribe francês antes de 1831 e os levados para o Sul dos Estados Unidos entre 1807 e 1819, haja vista que as vidas subsequentes desses infelizes não teriam sido muito diferentes daquelas dos escravos das mesmas regiões. A maioria dos outros recapturados será considerada e está classificada, na Tabela 1 , de acordo com a nação

7 Para uma discussão desse tema, ver ELTIS, David. Economic Growth and the Ending of the Transatlantic Slave Trade. New York, 1987. 
que capturou os africanos - muito embora o destino desses recapturados frequentemente não seja claro.

Em um sentido, a Tabela 1 fornece uma visão ampla dos resultados das tentativas de supressão do tráfico durante o século XIX. Mais importante para nossos propósitos, ela mostra as embarcações e recapturados que proveram a base para a diáspora dos africanos livres - nesse caso distribuída de acordo com a nação que realizou a detenção inicial. A coluna 1 tabula as embarcações capturadas após 1808 que tinham e as que não tinham cativos a bordo no momento da detenção. As colunas 2 e 3, diversamente, só incluem os barcos com escravos a bordo na hora da captura e aqueles cujos cativos foram pegos após o desembarque. A coluna 2 mostra, até onde isso pode ser estimado, o número de escravos embarcados, ao passo que a coluna 3 fornece o número dos que sobreviveram até o desembarque. O contingente de cativos sobreviventes no momento da detenção não está incluído, mas o número de embarcações carreando escravos naquela hora está indicado entre parênteses, podendo ser comparado à quantidade total de navios negreiros detidos, presente na coluna 1. A nova base de dados permite estimar em cerca de 9.000 os navios negreiros que levaram ou tentaram levar escravos da África para as Américas após 1807. Desse número, sugere a Tabela 1 que menos de um quarto foi detido, enquanto apenas uma em cada três embarcações de tráfico interceptadas realmente levava escravos no momento da captura. O que isso significava para os cativos era que as esquadras antitráfico das potências navais atlânticas, combinadas, só conseguiram desviar de uma vida nas plantations americanas algo entre seis e sete por cento dos que foram forçados a entrar no tráfico atlântico de escravos ${ }^{8}$. De acordo com o perfil temporal do Gráfico 1, o pico das capturas ocorreu no final dos anos 1830 e nos últimos anos da década de 1840. As capturas eram evidentemente afetadas pelo volume do tráfico, mas as alternâncias da política de combate ao comércio conduziam a que os aprisionamentos não se limitassem a oscilar de acordo com os altos e baixos da atividade traficante. Sua importância relativa foi maior que nunca durante os anos 1830 .

8 É claro que nem todo o tráfico de escravos realizado após 1807 era ilegal e sujeito a proibições. O que particulariza o ano de 1807 é o fato de ter sido o da retirada da Inglaterra e dos Estados Unidos da atividade. O tráfico para Cuba, muito grande, foi legal até 1820 e aquele para o Brasil, até 1830. Um cálculo das taxas de captura que levasse isso em conta dobraria a parcela dos escravos capturados. No entanto, as esquadras antitráfico que operavam no Atlântico nunca chegaram perto da consecução de seu objetivo (ver ELTIS, Economic Growth). 
TABELA 1 - AFRICANOS E EMBARCAÇÕES DE TRÁFICO DE ESCRAVOS DETIDAS ENTRE 1808 E 1866, SEGUNDO A BANDEIRA E A NAÇÃO CAPTORA

\begin{tabular}{l|c|c|c}
\hline $\begin{array}{c}\text { Nação responsável } \\
\text { pela detenção }\end{array}$ & $\begin{array}{c}\text { Navios negreiros } \\
\text { detidos }\end{array}$ & $\begin{array}{c}\text { Africanos } \\
\text { embarcados }^{1}\end{array}$ & $\begin{array}{c}\text { Africanos } \\
\text { desembarcados }^{1}\end{array}$ \\
\hline Inglaterra & 1.575 & $183.704(656)$ & $162.071(656)$ \\
\hline Espanha & 39 & 0 & 0 \\
\hline Portugal & 57 & $1.811(4)$ & $1.683(4)$ \\
\hline França & 214 & $572(5)$ & $511(5)$ \\
\hline Estados Unidos & 68 & $7.107(10)$ & $6.212(10)$ \\
\hline Brasil & 30 & $7.208(13)$ & $5.861(13)$ \\
\hline Haiti & 3 & $903(3)$ & $808(3)$ \\
\hline Total & 1.985 & $201.305(691)$ & $177.146(691)$ \\
\hline
\end{tabular}

NOTAS:

${ }^{1}$ Inclui seis navios negreiros naufragados em território britânico e para os quais não se localizou nenhum processo judicial.

FONTES: TSDT2 em www.slavevoyages.org

\section{FIGURA 1 - AFRICANOS RECAPTURADOS RETIRADOS DO TRÁFICO ATLÂNTICO DE ESCRAVOS APÓS 1807, POR QUINQUÊNIOS}

Figure 1 Re-captive Africans Diverted from the Transatlantic Slave Trade after 107, by Five year Periods

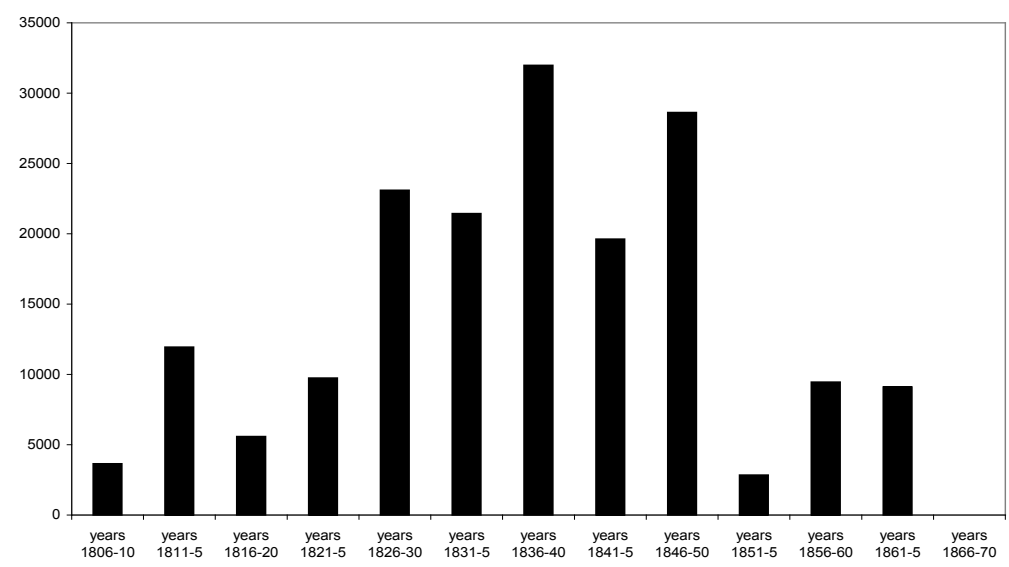


Como foi observado acima, quase sempre os cativos libertados dos navios negreiros (ou, em muito poucos casos, resgatados de senhores de escravos antes de embarcados ou depois de desembarcados) passaram por um processo legal que proclamou formalmente seu novo estatuto. O mais bem conhecido desses processos era a adjudicação realizada por Comissões Mistas - tribunais internacionais resultantes de uma série de tratados entre os ingleses e vinte outras nações, os quais foram estabelecidos em diferentes momentos em Serra Leoa, Luanda, Cabo da Boa Esperança, Rio de Janeiro, Paramaribo (Suriname), Kingston (Jamaica), Havana e Nova York a fim de processar embarcações suspeitas de tráfico de escravos. Nada menos que 86.012 africanos passaram por esses tribunais - metade de todos os africanos recapturados. A grande maioria deles - 65.859 - passou pelas várias Comissões Mistas de Serra Leoa, tendo ainda 14.216 outros sido liberados em Havana e 6.528 no Rio de Janeiro. As Comissões Mistas de outros locais não libertaram efetivamente nenhum escravo. Um segundo grande grupo de 73.114 foi declarado liberto pelo sistema de tribunais domésticos ingleses com jurisdição sobre assuntos marítimos. Eram chamados Tribunais do Almirantado e se dividiam em uma corte de apelação, o Alto Tribunal do Almirantado, e tribunais de mais baixa instância chamados Tribunais do Vice-Almirantado, existindo um deles em quase toda possessão britânica que tivesse uma linha de costa. Os tribunais internos de outras nações libertaram mais 14.915 africanos. Brasil (5.861) e os Estados Unidos (6.212) compuseram o núcleo desse grupo, mas os tribunais portugueses na África (1.683), assim como os franceses (362) também contribuíram. Finalmente, os historiadores ignoraram amplamente o papel do novo governo do Haiti, cuja marinha deteve navios negreiros entre 1811 e 1819, os quais carreavam 808 africanos. Os ingleses libertaram outros três mil africanos, aparentemente sem recorrer a processos judiciais. A maior parte destes naufragou nas ilhas do Caribe inglês a caminho de Cuba. Agrupar todos esses dados classificando-os em jurisdições do Velho Mundo, de um lado, e jurisdições do Novo Mundo, de outro lado, conduz à conclusão de que a grande maioria dos africanos livres, embora depositada ou reassentada a milhares de milhas de seus lugares de origem, nunca deixou efetivamente o continente africano. Apesar de terem recebido, de longe, a maior parte da atenção dos estudiosos, apenas $20 \%$ dos recapturados foram libertados nas Américas. 
De fato, como já foi notado, o número total de africanos livres não pode ser considerado trivial pelos estudiosos que buscam compreender a diáspora africana, mas também não era uma amostra representativa das pessoas forçadas a realizar a travessia da África para as Américas no século XIX, e muito menos de todos os cativos transportados durante a era do tráfico de escravos. A Tabela 2 mostra as partes da costa africana onde foram embarcados os do grupo de recapturados, comparando essa distribuição com

TABELA 2 - LITORAIS AFRICANOS DE EMBARQUE DOS AFRICANOS LIVRES COMPARADOS AOS DE TODOS OS CATIVOS, DOIS PERÍODOS, 1808-1867

\begin{tabular}{|c|c|c|c|c|}
\hline \multirow{3}{*}{ 1808-1839 } & \multicolumn{2}{|c|}{ Africanos livres } & \multicolumn{2}{|c|}{ Todos os cativos } \\
\hline & & & & \\
\hline & Cativos & $\%$ coluna & Cativos & $\%$ coluna \\
\hline Senegambia & 1.901 & 1,9 & 34.778 & 2,3 \\
\hline Serra Leoa & 11.022 & 11,0 & 43.999 & 2,9 \\
\hline $\begin{array}{l}\text { Costas da Malagueta e do } \\
\text { Marfim }\end{array}$ & 2.426 & 2,4 & 8.005 & 0,5 \\
\hline Costa do Ouro & 1.088 & 1,1 & 6.789 & 0,5 \\
\hline Golfo de Benim & 30.997 & 31,0 & 147.745 & 9,8 \\
\hline Golfo de Biafra & 37.163 & 37,2 & 158.449 & 10,6 \\
\hline $\begin{array}{l}\text { África Centro-Ocidental } \\
\end{array}$ & 11.109 & 11,1 & 885.505 & 59,0 \\
\hline Sudeste africano & 3.185 & 3,2 & 215.380 & 14,4 \\
\hline Total & 99.898 & 100,0 & 1.500 .649 & 100,0 \\
\hline \multicolumn{5}{|l|}{ 1840-1867 } \\
\hline & Cativos & $\%$ coluna & Cativos & $\%$ coluna \\
\hline Senegambia & 279 & 0,4 & 3.653 & 1,1 \\
\hline Serra Leoa & 2.899 & 4,3 & 10.671 & 3,1 \\
\hline $\begin{array}{l}\text { Costas da Malagueta e do } \\
\text { Marfim }\end{array}$ & 0 & 0,0 & 500 & 0,1 \\
\hline Costa do Ouro & 0 & 0,0 & 507 & 0,1 \\
\hline Golfo de Benim & 15.660 & 23,4 & 56.730 & 16,5 \\
\hline Golfo de Biafra & 974 & 1,5 & 9.348 & 2,7 \\
\hline África Centro-Ocidental & 42.692 & 63,7 & 224.634 & 65,5 \\
\hline Sudeste africano & 4.545 & 6,8 & 36.802 & 10,7 \\
\hline$\overline{\text { Total }}$ & 67.049 & 100,0 & 342.845 & 100,0 \\
\hline
\end{tabular}

FONTES: TSDT2 em www.slavevoyages.org 
aquela de todos os deportados a partir de 1807. Como as origens dos cativos na costa se alteraram dramaticamente ao longo do tempo, a tabela apresenta dois períodos - antes e depois de 1839. Durante o primeiro período, quando $60 \%$ dos cativos foram libertados, uma proporção esmagadora veio da África Ocidental, com Serra Leoa e os golfos de Benim e Biafra sediando os pontos de partida de mais que quatro em cada cinco dos que, em sua maior parte, lograram evitar a escravidão de plantation nas Américas. Como mostra o lado direito da tabela, apenas um quinto do total de embarques escravos veio dessas três regiões. A partir de 1839, em contraste, os recapturados tornaram-se muito mais representativos da composição do grupo que foi empurrado para o tráfico de escravos.

As partes da costa onde embarcaram contam-nos alguma coisa sobre quem foram os recapturados, mas não precisamos ficar nisso. $\mathrm{O}$ tráfico atlântico de escravos sempre foi dominado por um número relativamente pequeno de portos de embarque principais. À exceção do que ocorria na Costa da Malagueta e na Costa do Marfim', os navios negreiros usualmente não compravam escravos em pontos dispersos por uma linha de costa muito grande. No século XIX, a tendência a procurar o carregamento humano em apenas uma locação tornou-se ainda mais pronunciada. Como mostra a Tabela 3, os golfos de Benim e Biafra e a África Centro-Ocidental proveram $83 \%$ de todos os africanos libertados no século XIX. A região de Serra Leoa, embora uma zona de procedência menos importante que as três anteriores, gerou outros $13 \%$. Três dessas quatro regiões foram dominadas, cada uma, por apenas dois grandes pontos de embarque. Mais de quatro em cada cinco deportados a partir do golfo de Benim passaram por Uidá (Whydah) ou Lagos. Quase três quartos dos que saíram do golfo de Biafra foram embarcados em Bonny ou Old Calabar, ao passo que dois terços dos saídos da Alta Guiné passaram por Galinhas ou pelo rio Pongo antes de 1840. O padrão das saídas na grande área da África Centro-Ocidental era ligeiramente menos concentrado no período inicial (1808-1839), mas a Ambriz, Luanda, Benguela, o rio Congo e Cabinda corresponderam dois terços das partidas ao longo de todo o período, com o domínio das três primeiras áreas antes de 1840 e das três últimas após 1839 - momento a partir do qual

9 Windward Coast, no original. Como "Costa de Barlavento" não é e nem era usual em português, traduzi como "Costa da Malagueta e Costa do Marfim", seguindo, por exemplo, FIGANIÉRE, Joaquim César de. Descripção de Serra-Leôa e seus contornos. Lisboa: Impressão de João Batista Morando, 1822 (N. do T.). 
TABELA 3 - REGIÕES DE DESEMBARQUE DE AFRICANOS LIVRES - CHEGADAS INICIAIS COMPARADAS AOS DESTINOS FINAIS, 1808-1867

\begin{tabular}{|c|c|c|c|}
\hline & & \begin{tabular}{|c|}
$\begin{array}{c}\text { Chegadas após } \\
\text { a recaptura }\end{array}$ \\
\end{tabular} & $\begin{array}{l}\text { Movimento subsequente } \\
\text { (líquido) }\end{array}$ \\
\hline \multicolumn{4}{|c|}{ Caribe inglês } \\
\hline & Tortola & 2.122 & -107 \\
\hline & Antigua & 1.711 & Desconhecido \\
\hline & Dominica & 568 & Desconhecido \\
\hline & Barbados & 593 & Desconhecido \\
\hline & Grenada & 1.100 & +800 \\
\hline & Trinidad & 195 & +8.905 \\
\hline & Jamaica & 2.919 & +9.810 \\
\hline & Bahamas & 6.077 & +891 \\
\hline & Guiana Inglesa & 314 & +15.528 \\
\hline & Honduras & 713 & +500 \\
\hline & Outros - Caribe Inglês & 74 & +2.963 \\
\hline \multicolumn{4}{|c|}{ Estados Unidos } \\
\hline & Estados Unidos & 6.894 & +6.848 \\
\hline \multicolumn{4}{|l|}{ Cuba } \\
\hline & Cuba & 11.207 & -7.092 \\
\hline \multicolumn{4}{|c|}{ Caribe Francês } \\
\hline & Martinica & 281 & 0 \\
\hline & Guadalupe & 422 & 0 \\
\hline \multicolumn{4}{|l|}{ Haiti } \\
\hline & Haiti & 808 & 0 \\
\hline \multicolumn{4}{|l|}{ Brasil } \\
\hline & Bahia & 524 & Desconhecido \\
\hline & Sudeste brasileiro & 13.422 & -1.718 \\
\hline \multicolumn{4}{|c|}{ África } \\
\hline & Senegal & 122 & 0 \\
\hline & Serra Leoa & 94.787 & -16.841 \\
\hline & Monróvia & 763 & +6.449 \\
\hline & Castelo de Cape Coast & 45 & 0 \\
\hline & Fernando Pó & 232 & -232 \\
\hline & Lagos & 0 & +1.500 \\
\hline & Luanda & 1.683 & 0 \\
\hline & Cabo da Boa Esperança & 4.511 & Desconhecido \\
\hline \multicolumn{4}{|c|}{ Outros } \\
\hline & Santa Helena & 23.915 & -14.858 \\
\hline & Mauritius & 1.186 & 0 \\
\hline Total & & 177.189 & \\
\hline
\end{tabular}

Fontes: TSDT2 em www.slavevoyages.org; KOPYTOFF, op. cit., p. 61; ADDERLEY, op. cit., p. 241-48, ASIEGBU, op. cit., p. 189, MURRAY, Odious Commerce, op. cit.; LAWRENCE, K. O. Immigration into Trinidad and British Guiana, 1834-1870. PhD, University of Cambridge, 1958. 
a concentração geográfica aumentou substancialmente. Assim, de 1808 a 1839, eram de mais de cinquenta por cento as chances de que um africano livre tivesse passado por Uidá, Lagos, Bonny e Calabar - abrangendo apenas um pouco mais que trezentas milhas quadradas do que são hoje o Benim e a Nigéria. Se estendermos um pouco essa área para que ela inclua Popó Grande, no Oeste, e os Camarões, no Leste, além dos pontos menos importantes de embarque situados entre Popó Grande e os Camarões - tais como Porto Novo, Badagry, Nova Calabar etc - concluiremos então que dois em cada três recapturados foram levados para os navios negreiros na costa oriental do golfo de Benim e na parte norte do de Biafra. Após 1839, a concentração geográfica aumentou ainda mais, tendo por outro lado se concentrado, nesse período, na África Centro-Ocidental. Entre oito e nove de cada dez cativos embarcou a partir dos quatro portos de Cabinda, do rio Congo, de Ambriz e de Benguela. Do mesmo modo que a faixa de costa entre Popó Grande e os Camarões, aquela entre Cabinda e Benguela mede aproximadamente quinhentas milhas.

Para além da geografia costeira, existe a questão do perfil das origens geográficas dos cativos no interior ${ }^{10}$, o que os registros de africanos livres das Comissões Mistas dão margem a identificar, em suas grandes linhas. Eles contêm os nomes africanos e, para alguns, a área de origem das pessoas libertadas pelos tribunais. Muitos desses nomes podem ser encontrados em mais de uma cultura e, mesmo quando este não é o caso, a ligação de uma localização com a identificação expressa nem sempre é direta. Além do mais, apenas alguns milhares desses registros foram identificados até o momento. A pesquisa, no entanto, já fez emergirem novos detalhes sobre a ligação entre origens e portos de embarque. Como mostra o Mapa 1, a maior parte dos recapturados que haviam embarcado no rio Pongo, ao Norte do estuário de Serra Leoa, tinha vindo de regiões situadas a 100 ou 150 milhas de distância, compreendendo grupos amplamente dispersos. Os Kissi, Mandinga, Susu, Mende, Temne e Fula compuseram mais de $80 \%$ daqueles que embarcaram entre 1824 e 1841 , sem que qualquer grupo preponderasse. O mesmo padrão de dispersão prevaleceu em Galinhas e em outros pontos de menor importância no Sul da área de Serra Leoa, mas

10 ADDERLEY, "New Negroes From África”, op. cit., p. 92-125, usa os dados sobre origens dos registros da Comissão Mista de Havana como base para sua discussão sobre etnicidade de 10.389 recapturados, mas não explora as implicações étnicas de seus nomes. 
um grupo, o dos Mende, foi responsável por mais de um terço da amostra, estando também representados os outros da lista do rio Pongo - cada um com aproximadamente dez por cento. Isso sugere grande diversidade das proveniências ${ }^{11}$.

Como Phil Misevich apontou, isso contrasta fortemente com o padrão em geral concentrado das origens dos casos dos Camarões e do Oriente do golfo de Biafra - outra região para a qual os nomes dos cativos formaram a base de uma análise das procedências dos recapturados. Neste caso, como mostra o Mapa 2, cerca de $60 \%$ dos recapturados foram fornecidos por uma área relativamente pequena, estendendo-se por 200 milhas ao Noroeste do estuário do rio Camarões através do bojo ocidental do que é hoje a República dos Camarões. Esta área compreende apenas 20\% do território do país atual. Os grupos Tikari, Duala-Bimbia, Banyangi e Bakossi compuseram essa maioria. A área mais pesadamente populosa ao Norte do país foi responsável por apenas cinco por cento dos recapturados, compostos principalmente por povos $\mathrm{Chamba}^{12}$. O mesmo enviezamento da distribuição é visível em outras partes da região. Alguns grupos populosos e proeminentes, como os Bamileke, estão em geral muito pouco representados. Isso é bem diferente da amostra de Serra Leoa, onde todos os grupos principais que se sabe terem vivido na área durante o século XIX podem ser encontrados nas listas de recapturados.

Quanto ao sertão dos outros lugares centrais de embarque de recapturados para as Américas, é impossível até o momento analisar origens de modo mais refinado, embora a discussão precedente sobre Serra Leoa e os Camarões sugira que logo ela será viável. Por intermédio das colunas de áreas de procedências dos registros de Havana, confrontadas com os nomes individuais dos recapturados, sabemos o suficiente para classificar a ampla amostragem de nomes em Ioruba e não Ioruba, e esse procedimento sublinha a predominância dos primeiros. Aparentemente, $99 \%$ dos saídos de Lagos, $80 \%$ dos de Uidá e $12 \%$ dos recapturados despachados de Popó se autoidentificavam como Ioruba. Mais de seis em cada dez dos recapturados

11 MISEVICH, Philip. The Origins of Slaves Leaving the Upper Guinea Coast in the Nineteenth Century. In: ELTIS, David; RICHARDSON, David (Org.). Extending the Frontiers: Essays on the New Transatlantic Slave Trade Database. New Haven, p. 155-175, 2008.

12 Este parágrafo se baseia em NWOKEJI, Ugo Nwokeji; ELTIS, David. Characteristics of Captives Leaving the Cameroons for the Americas, 1822-1837. Journal of African History, v. 43, p. 191-210, 2002. 
ELTIS, D. O significado da investigação sobre os africanos escapados...

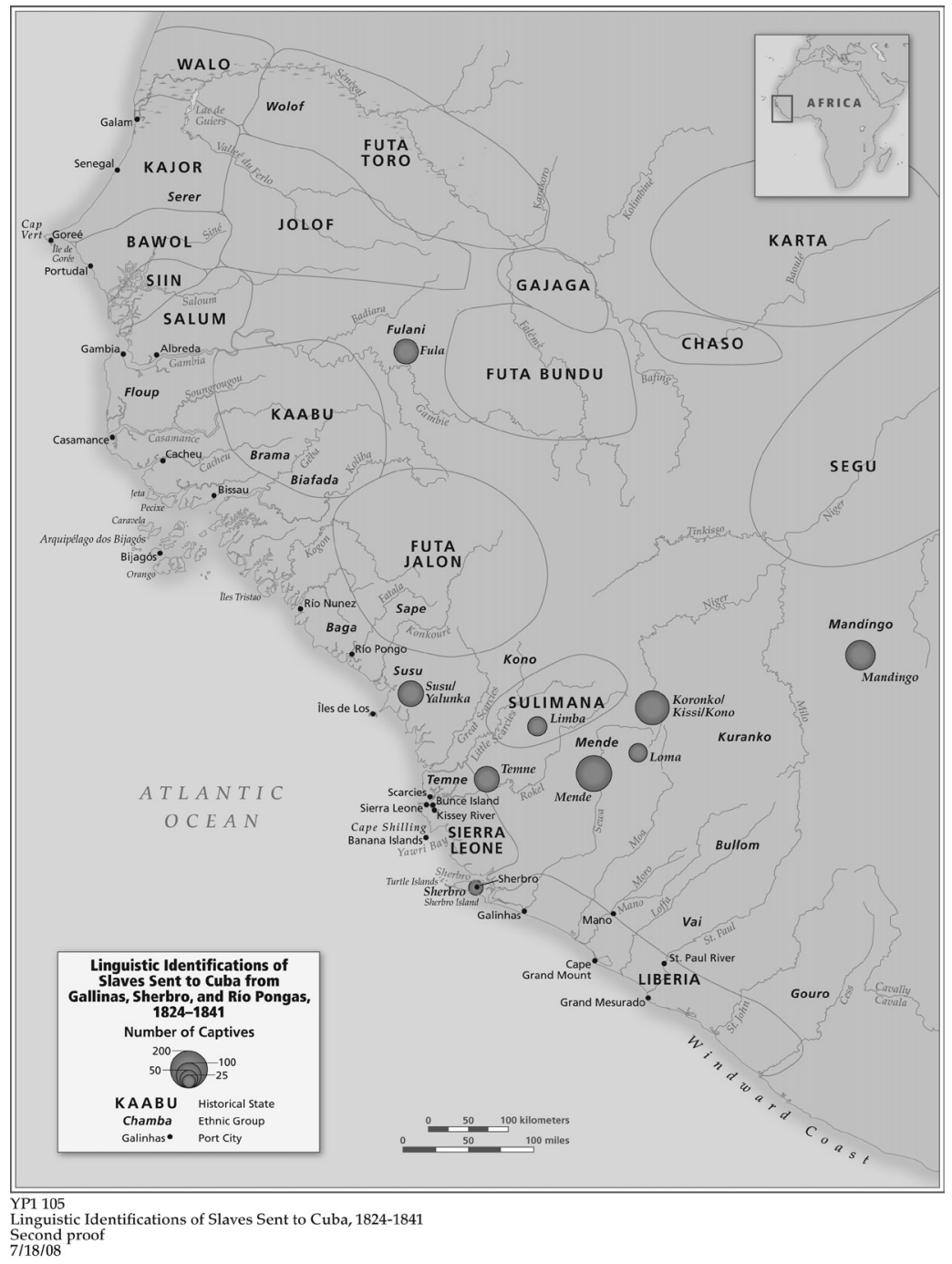

História: Questões \& Debates, Curitiba, n. 52, p. 13-39, jan./jun. 2010. Editora UFPR 


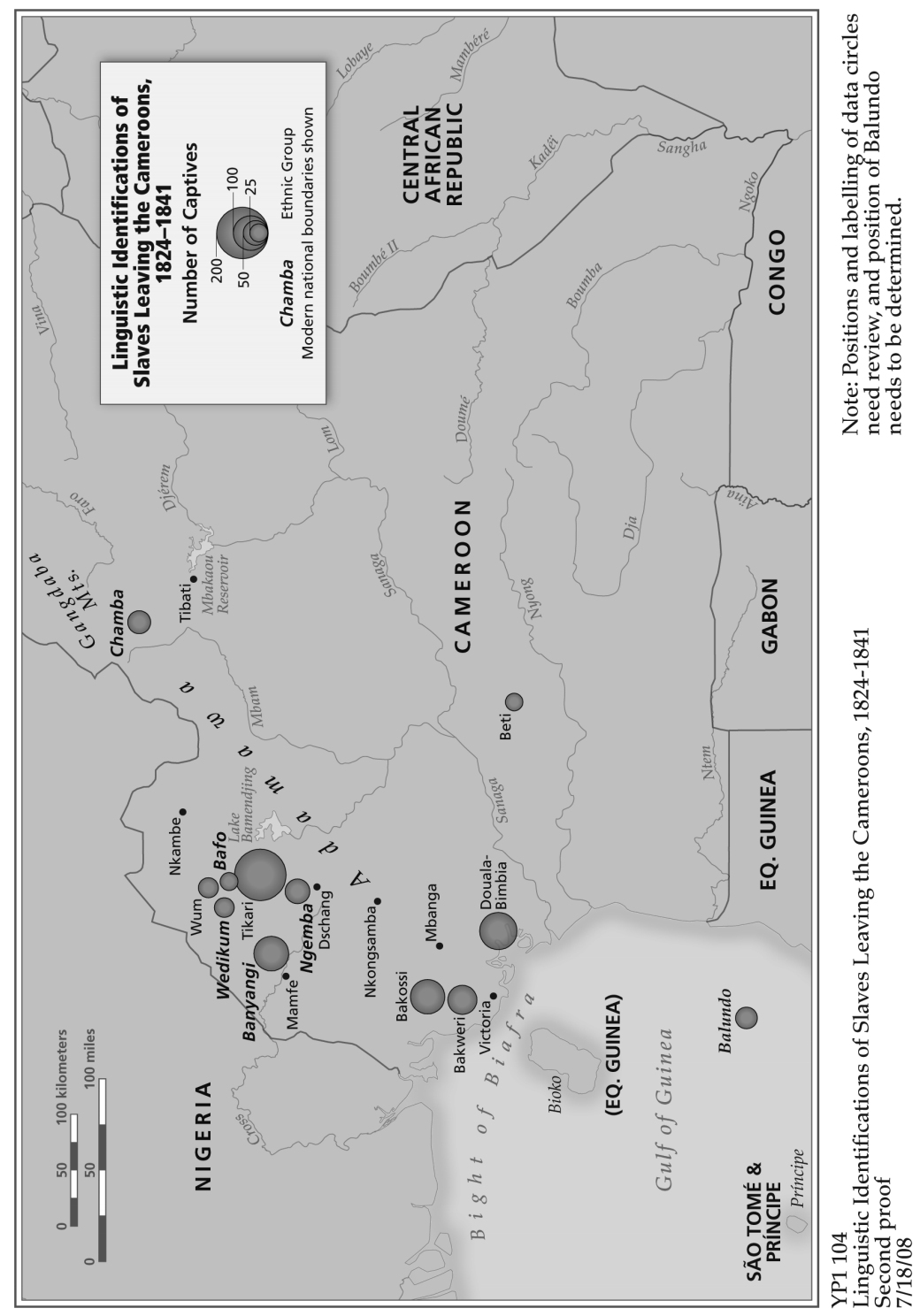


que haviam saído pelo golfo de Benim eram Ioruba, com metade deste grupo associado a Oyo. Quase todos os não Ioruba eram Ewe-Fon, proporção que, completado o trabalho de base com os nomes africanos, provavelmente será suficiente para situar as principais subcategorias Ewe-Fon entre as cinco (ou algo em torno disso) mais importantes identidades da diáspora dos recapturados ${ }^{13}$. Ainda não se tem muito o que mostrar quanto ao golfo de Biafra e à enorme área da África Centro-Ocidental, mas os avanços, aqui, também são iminentes, e, no caso de Bonny e de Old Calabar, ainda não há nada que contradiga a expectativa de que povos Igbo formaram uma forte maioria. Assim, para os golfos de Benim e Biafra, logo contaremos com muito maior precisão e bastante mais detalhes a adicionar ao perfil das deportações, embora nenhuma surpresa mais importante seja provável.

Em contraste, no tocante a Luanda, Benguela, Ambriz, Cabinda e rio Congo, os pontos de embarque mais importantes da África Centro-Ocidental (e, de fato, de toda a África subsaariana a partir de 1839), o material novo desafiará consensos anteriormente prevalecentes entre os estudiosos. Como o primeiro ponto a ser notado aqui, enquanto a Tabela 2 mostra ter sido a amostra de recapturados para essa ampla área tão grande quanto a de outras regiões de embarque, a informação personalizada disponível para a amostragem de 53.801 africanos é bem mais fraca que a da África Ocidental. As jurisdições brasileiras e portuguesas pelas quais a maior parte deste grupo passou não registraram, em sua maioria, os nomes africanos e as origens dos recapturados. Esse tipo de informação só sobreviveu para cerca de 3.000 pessoas desse grupo, tendo todas passado pelas Comissões Mistas de Serra Leoa e Havana. Felizmente sobreviveram fontes importantes para um grupo de escravos angolanos relacionado com este. Em 1855, o governo português estabeleceu um registro de escravos e da posse de escravos na colônia, ostensivamente como um passo inicial para regular e abolir a instituição da escravidão. Há nomes africanos para cerca de metade dos aproximadamente 25.000 escravos dos registros sobreviventes, e origens para quase todos. Esse material recebeu tratamento informatizado graças aos esforços de Roquinaldo Ferreira e Daniel Domingues da Silva. Este último realizou uma análise preliminar dos registros de recapturados combinada com a de

13 ELTIS, David. The Diaspora of Yoruba-Speakers, 1650-1865: Dimensions and Implications. In: FALOLA, Toyin; CHILDS, Matt (Org.). The Yoruba Diaspora in the Atlantic World. Bloomington, p. 3-26, 2005. 
alguns dos registros angolanos de escravos, tendo descoberto que o Império Lunda do Oriente angolano provavelmente foi muito menos importante como fonte de cativos no século XIX do que os historiadores pensaram ${ }^{14}$. De fato, os recapturados parecem ter tido suas origens em áreas do Norte e do Sul da Angola portuguesa, ao invés de terem resultado da atividade Lunda. Os recapturados muito provavelmente vieram das regiões Congo e Ovimbundu, o que constitui um grande desvio frente ao quadro pré-1830 desenhado por Joseph C. Miller ${ }^{15}$.

As origens definitivas desse grupo de africanos serão mais bem esclarecidas nos próximos anos, continuando-se o trabalho com a base de dados formada com os registros de africanos libertados. As implicações para os interessados na influência africana nas Américas são consideráveis. Cerca de dois terços, ou 44.000 pessoas, do grupo para o qual é possível rastrear procedências africanas estavam a caminho de Cuba no momento de sua detenção. Outros 12.000 estavam destinados a Salvador, na Bahia, 7.000 para o Rio de Janeiro e 1.500 para o Recife. Não há razão para crer que o substrato cultural desses africanos tivesse que ser de alguma forma diferente daquele do grupo de migrantes forçados cuja viagem transatlântica não foi interrompida. A captura em alto mar era um evento aleatório no que tocava ao substrato daqueles detidos abaixo dos conveses, e pode-se presumir que qualquer conclusão obtida quanto aos recapturados pode ser aplicada ao conjunto mais amplo dos que completaram a travessia atlântica como planejado. Até este momento, os estudiosos só foram capazes de identificar as origens precisas de um número pequeno de cativos africanos nas Américas. Para números maiores de escravos, tem sido possível usualmente identificar apenas o porto de embarque na África, ou, mais raramente, as grandes categorias etnolinguísticas às quais eles provavelmente pertenciam. Para isso, inclusive, os estudiosos tiveram que basear-se em designações atribuídas por senhores de escravos - Lucumi, Nagô ou Congo. Os registros de africanos livres criados pelas Comissões Mistas logo nos permitirão ligar,

14 SILVA, Daniel B. Domingues da. The Origins of Slaves Leaving Angola in the $19^{\text {th }}$ Century: Primary Results from Field Work. Unpublished paper presented to the European Social Science History Conference, Lisbon, February, 2008; FERREIRA, Roquinaldo. The Suppression of the Slave Trade and Slave Departures from Angola, 1830s-1860s. In: ELTIS; RICHARDSON (Org.). Extending the Frontiers, op. cit., p. 313-34.

15 MILLER, Joseph C. Way of death: merchant capitalism and the Angolan slave trade, 17301830. Madison, Wisc.: The University of Wisconsin Press, 1988. 
muito mais extensamente do que já foi possível, destinos nas Américas (mesmo que só houvesse a intenção de levar africanos a esses lugares) com línguas, culturas e origens geográficas na África. Por exemplo, num futuro próximo será possível criar mapas semelhantes aos de números 1 e 2 para os escravos que chegaram em Salvador nos anos 1820 e 1830.

Tendo revisado o estado presente dos conhecimentos sobre as origens e as destinações projetadas da diáspora de recapturados, devemos agora tentar rastrear os destinos efetivos do grupo após a libertação. Quanto à maioria, podemos dizer alguma coisa sobre sua destinação imediata, à medida que a encontramos saindo de um processo judicial que mudava formalmente seu estatuto, de cativos para africanos livres. Mas até isso constitui um avanço diante dos conhecimentos disponíveis. O primeiro ponto a ser notado é o de que, ao passo que alguns navios negreiros foram capturados apenas alguns dias após terem feito vela, a grande maioria dos recapturados experimentou uma travessia pouco diferente em mortalidade e morbidade da que teria sido vivenciada caso tivesssem sido vendidos com sucesso a senhores de escravos brasileiros ou cubanos ${ }^{16}$. A razão disso estava no fato de as doenças - a causa da esmagadora maioria das mortes de cativos - terem sido tão prováveis nos barcos sob controle dos proprietários ou captores originais quanto nos navios de patrulha antitráfico. À exceção das viagens partidas da Alta Guiné, a maioria das detenções de embarcações só aconteceu em locais muitas semanas distantes, em tempo de navegação, dos lugares sob a jurisdição de quem os libertaria, ou mesmo após os cativos já terem enfrentado a travessia. Como consequência, muitos africanos livres morreram após a captura. Os números das Tabelas 1 e 2 refletem, majoritariamente, os africanos a bordo no momento da chegada das embarcações aos portos. Os cativos que permaneceram vivos tempo suficiente para serem formalmente libertados eram no mínimo 5\% menos numerosos que os referidos nessas tabelas.

Caso eles sobrevivessem à viagem e ao intervalo imediatamente subsequente, um leque extraordinariamente amplo de destinos potenciais os aguardava. Já chamei a atenção para os escravos interceptados pelas marinhas de governos favoráveis aos interesses dos plantadores, tendo optado por excluí-los da análise porque estes cativos permaneceram escra- 
vizados. Assim, as capturas francesas anteriores a 1832 não são contadas aqui, pois até onde sei elas não levaram a qualquer mudança de estatuto dos encontrados a bordo de navios negreiros ${ }^{17}$. De forma análoga, quando a marinha norte-americana capturava escravos antes da emenda de 1819 à abolição do tráfico ${ }^{18}$, os recapturados eram entregues ao estado para o qual a embarcação antitráfico levava sua presa. Exceto no caso de duas apreensões, tais estados ficavam sempre ao Sul da linha Mason-Dixon, tendo os cativos sempre sido vendidos no interior da população escrava. Finalmente, as autoridades cubanas e a marinha espanhola interceptaram 14.417 escravos entre 1854 e 1866. Embora esses atos tenham trazido prejuízos aos traficantes de cativos, cada um desses escravos incorporou-se à população escrava cubana através do suborno aos funcionários encarregados do cumprimento da lei. Nenhum deles está incluído entre os africanos livres ${ }^{19}$. Para os que o estão, no entanto, a Tabela 3 mostra para onde os recapturados foram levados depois de sua embarcação ter sido interceptada. A coluna 1 mostra o número de desembarcados em cada região, ao passo que a coluna 2 tenta traçar a subsequente realocação dos africanos livres para (sinal de mais) ou $d e$ (sinal de menos) cada região. Onde quer que as células da tabela estejam marcadas com "desconhecido" podemos assumir que os movimentos em qualquer das duas direções foram muito pequenos.

A coluna 1 da Tabela 3 mostra que um pouco mais que metade de todos os africanos livres desembarcou inicialmente na África, pouco mais de um terço nas Américas e cerca de $12 \%$ na pequena ilha de Santa Helena. O Caribe britânico (18.000), o Brasil (14.000) e Cuba (11.000) foram as principais destinações iniciais dos desembarques, ao passo que, no lado africano, Serra Leoa absorveu mais que o restante do mundo atlântico combinado. Mas a coluna 2 mostra que muitos africanos livres não permaneceram nos locais para onde foram inicialmente levados dos navios negreiros. Segundo

17 KIELSTRA, Michael, op. cit.; DAGET, Serge, op. cit.

18 "An Act in addition to the Acts prohibiting the slave trade", Act of March 3, 1819, Stat 532, citado por FINKELMAN, Paul. Regulating the African Slave Trade. Civil War History, v. 54, 2008, estabeleceu o retorno dos recapturados para a África, o que, de fato, significava a Libéria. Dois casos de embarcações norte-americanas de tráfico capturadas em 1800 e trazidas para a Filadélfia por um capitão abolicionista resultaram na transformação de 45 recapturados em negros livres. Vide a Pennsylvania $G a$ zette, 7 e 20 de agosto de 1800 . Viagens 36992 e 36707 em http://slavevoyages.org/tast/database/search. faces? yearFrom $=1800 \&$ yearTo $=1800 \&$ mjslptimp $=20900$.

19 MURRAY, David. Odious Commerce: Britain, Spain, and the Abolition of the Cuban Slave Trade. Cambridge, 1980, p. 288. 
os dados da mesma coluna, cerca de um quarto dos recapturados mudou-se para outras áreas, algumas vezes voluntariamente, outras não. Como se sabe, as principais rotas desses deslocamentos levavam das Américas ibéricas para o Caribe inglês, destino também dos de Serra Leoa e especialmente dos de Santa Helena. O Caribe britânico, desse modo, configurou-se, de longe, como o mais importante receptor de africanos livres, à exceção de Serra Leoa. Somando-se os chegados diretamente e os indivíduos realocados, aquela área provavelmente recebeu 55.000 recapturados. Um ramo menor dos africanos livres foi do Oeste para o Leste - dos Estados Unidos para a Libéria.

Ainda mais interessante que a geografia do assentamento dos recapturados é o estatuto dos africanos livres após eles terem passado pelos processos judiciais deslanchados por sua interceptação. Um certificado passado por uma Comissão Mista e uma identificação em seus registros não constituíam plena garantia de que um recapturado conseguiria evitar o destino daqueles detidos pelos primeiros navios de patrulha franceses e norte-americanos, ou pelos cubanos após 1854. Alguns daqueles assentados em aldeias de Serra Leoa terminariam sequestrados por traficantes de escravos na área circundante e enviados para o Atlântico em uma segunda travessia (de fato, tal possibilidade foi uma das principais razões para que as Comissões Mistas criassem um sistema assim tão elaborado de registro). De modo semelhante, o grupo muito mais amplo dos 5.321 emancipados que haviam sido originalmente capturados pelos ingleses e levados ante a Comissão Mista de Havana antes de 1833 em sua maioria desapareceu no interior da força de trabalho escrava das plantations do Ocidente cubano. No início dos anos 1840, 1.200 deles foram entregues aos ingleses, mas um número indeterminado, certamente a maioria, permaneceu em Cuba, presumivelmente até o fim da escravidão em $1886^{20}$. Só em 1833 os espanhóis concordaram com a imediata realocação dos recém-surgidos emancipados em colônias do Caribe britânico, principalmente as Bahamas e Trinidad ${ }^{21}$.

20 Há uma dificuldade aqui: é improvável que muitos dos supostos emancipados entregues aos ingleses após os anos 1840 pelas autoridades cubanas para transferência a colônias britânicas tenham alguma vez sido realmente libertados pela Comissão Mista. Ao invés disso, tratava-se de "[desordeiros] de condição livre, ou negros que não tinham mais valor para seus proprietários". David Turnbull, citado por MURRAY. Odious Commerce, op. cit., p. 281. A melhor discussão sobre os emancipados está nas p. 271-297 desse trabalho.

21 Para uma discussão desse processo, ver ADDERLEY, "New Negroes From África”, e MURRAY, Odious Commerce. 
No Brasil, igualmente, os cativos a bordo de navios negreiros levados aos tribunais brasileiros para adjudicação terminaram suas vidas como escravos, tendo isso resultado de subornos a funcionários encarregados do cumprimento da lei por donos de navios negreiros. No entanto, esses casos foram bem mais raros que em Cuba. De modo geral, talvez, 7.000 recapturados, ou quatro por cento de todos os africanos livres, terminaram suas vidas (ao menos enquanto a escravidão persistiu) como escravos no sentido pleno da palavra.

Um destino ainda pior aguardava muitos dos adjudicados na ilha inglesa de Santa Helena durante os anos 1840. Santa Helena se localizava a um terço do trajeto através do Atlântico partindo da África, e foi tornada um depósito de africanos livres pelos britânicos quando o principal de seu esforço de supressão do tráfico se deslocou para o Sul em seguida a 1840. Nas capturas feitas no Atlântico Sul, a marinha havia tido que fazer face a longas viagens para Serra Leoa, envolvendo meses no mar e muitas mortes. Embora os recapturados estivessem seguros de que a reescravização não ocorreria, o experimento, em seu conjunto, foi um desastre epidemiológi$\mathrm{co}^{22}$. A ilha era fria e sujeita a fortes ventos. As doenças gastrointestinais e pulmonares eram comuns, e muitos daqueles que não foram removidos da ilha para outras partes do Atlântico acabaram não sobrevivendo ${ }^{23}$.

Os noventa por cento dos recapturados que conseguiram evitar uma morte prematura podem ser divididos em dois grandes grupos. O menor dos dois agrupava os que adentraram uma vida de trabalho para outras pessoas como trabalhadores presos ao solo (predial laborer). A coluna 2 da Tabela 3 mostra que, nas colônias do Caribe inglês, a maior parte dos africanos livres foi recebida em última instância pelas que tinham os setores açucareiros mais ativos, tanto antes quanto depois da abolição. Trinidad, a Guiana Inglesa e a Jamaica produziram juntas quase a metade da produção total de açúcar de Cuba de 1860. Por essa época, o grosso da mão de obra, pelo menos no caso de Trinidad e da Guiana Inglesa, era fornecido pelo trabalho compulsório de asiáticos contratados. Essas três colônias inglesas

22 Manuel Barcia Paz, da Universidade de Leeds, prepara presentemente o primeiro estudo sobre o modo como os ingleses usaram Santa Helena como ponto de desembarque para recapturados. Tal estudo é muito urgente.

23 Para um relato estarrecedor, feito por um cirurgião naval, sobre as instalações de Lemon Valley, na ilha, ver Colonial Office to Palmerston, November 27, 1849, enc. "Dr. Vowell's Report", British National Archives, FO84/779, fls 175-215. 
dificilmente teriam recebido algum recapturado diretamente levado de navios negreiros capturados, mas foram o destino de 34.000 - ou seja, a grande maioria - dos africanos livres realocados a partir do local de seu desembarque original. Isso não foi um acidente, haja vista que a escassez de trabalhadores era nessas colônias maior que em qualquer outro lugar. Nelas, os salários eram mais altos que em Serra Leoa, e devem ter sido muito mais altos ainda que em Santa Helena, apesar de os recrutas enviados para as colônias açucareiras do Caribe terem sido, como prática usual, sujeitados a um ano de contrato de trabalho que continha compulsoriedade. Eles também tinham que suportar severas leis contra a vadiagem, as quais não tinham contrapartidas na África dessa época. E, embora os primeiros recrutados tenham recebido a promessa de passagem gratuita para seu retorno, essa cláusula havia desaparecido no início dos anos 1850 . Os estudiosos deram muita atenção aos estratagemas dos agentes de emigração, e a interceptação de navios negreiros estrangeiros foi interpretada como algo motivado em parte pela necessidade de obter trabalhadores para as colônias açucareiras ${ }^{24}$.

Também devem ser incluídos nessa categoria os mais de seis mil africanos livres enviados a Monróvia, na Libéria. Todos estavam a bordo de embarcações detidas por navios de patrulha norte-americanos após 1819 - data antes da qual os recapturados eram normalmente revendidos nos estados sulistas ${ }^{25}$. Mais da metade desses recapturados tinha sido mantida no Caribe e, como consequência, teve que aguentar duas travessias atlânticas e, portanto, uma experiência de mortalidade mais horrenda que a de qualquer outro grupo, incluindo a dos enviados a Santa Helena, que será discutida à frente. A maior parte do contingente era formado por crianças e, uma vez na Libéria, elas eram entregues em regime de aprendizado a famílias americano-liberianas. De acordo com as leis da Libéria, o prazo desse aprendizado variava de sete a quatorze anos, tendo provavelmente a idade tido uma influência fundamental na duração efetiva. Crianças pequenas e algumas mulheres foram entregues a postos missionários. De fato, uma parcela desproporcional dos recém-chegados trabalhou para as missões e

24 SCHUlER, Monica. “Alas, Alas, Kongo”: A Social History of Indentured African Immigration into Jamaica, 1841-1865. Baltimore, 1980; ASIEGBU. Slavery and the Politics of Liberation.

25 Esse parágrafo se baseia em YOUNGER, Karen Fisher. "Africa Stretches Forth Her Hands unto You": Female Colonization Supporters in the Antebellum United States (Ph.D. diss., Pennsylvania State Univ., 2006). Ver, deste autor, Liberia and the Last Slave Ships. Civil War History, v. 54, 2008. 
participou delas. Todas as relações de aprendizado eram subsidiadas pelo governo norte-americano. Isso sem dúvida ajuda a explicar por que os africanos livres eram geralmente bem recebidos, mas um fator adicional era o de que eles não faziam parte da população africana local, com a qual as missões tiveram muito pouco sucesso. Alguns dos recém chegados, ironicamente, terminaram por trabalhar no pequeno setor produtor de cana de açúcar que existiu por um breve intervalo na Libéria de meados do século. Um aspecto impressionante desse ramo do reassentamento dos africanos livres foi o quanto os recém chegados se misturaram com os colonos afro-americanos; em outras palavras, o quanto evitaram viver nas aldeias ou comunidades estabelecidas para acomodá-los.

Da perspectiva assumida aqui, destacam-se dois elementos da distribuição geral dos africanos libertados e de sua posterior realocação. O primeiro liga-se às enormes diferenças entre os papéis desempenhados por Serra Leoa e por Santa Helena nesse movimento. De 95.000 africanos livres em Serra Leoa, menos de 15.000 (excluindo-se os Kru e outros recrutados nativos da área) foram para as Índias Ocidentais. Em comparação com Santa Helena, é surpreendente quão poucos foram contratados para isso. Da pequena ilha do Atlântico Sul, diversamente, quase todos os recapturados sobreviventes foram realocados atravessando o Atlântico. É verdade que a Tabela 3 mostra apenas 14.598 deixando a ilha, mas uma grande parte da diferença entre esse número e os 24.000 que desembarcaram nela pode ser creditada às mortes ocorridas na ilha. Isso lança nova luz sobre a questão das escolhas permitidas aos africanos livres removidos de Santa Helena ${ }^{26}$. As condições na ilha eram estarrecedoras. Como na fome irlandesa e nos casos africanos em que a fome conduziu à escravização voluntária, quem teria feito uma escolha diferente? Não surpreende que, partindo de uma população de base correspondente a apenas um quarto do tamanho da de Serra Leoa, Santa Helena tenha despachado para o Caribe um número maior de pessoas. De qualquer modo, a grande maioria dos que migraram para essas colônias produtoras de açúcar a partir da África, de Santa Helena, do Rio de Janeiro e das Bahamas trabalhou por salário e em sua maior parte como trabalhadores braçais. Tratava-se talvez de 37.000, no total, e a eles

26 Para a melhor discussão sobre as escolhas no contexto dos terrenos dos africanos livres em Freetown e Lemon Valley, ver ADDERLEY. "New Negroes From Africa”, op. cit., p. 81-83. 
podemos adicionar os cerca de 11.000 africanos que foram libertados no Brasil, mas que não foram levados depois disso para o Caribe inglês. Diferentemente do ocorrido em Cuba, os africanos entregues às autoridades brasileiras pelas Comissões Mistas, ou, ao menos em alguns casos, liberados pelos tribunais brasileiros não eram levados furtivamente para dentro da economia de plantation local. A maior parte deles foi posta para trabalhar para autoridades municipais em um ambiente urbano sem receber salários ${ }^{27}$. Assim, de 177.000 africanos libertados, cerca de 48.000, ou pouco mais de um quarto, tornaram-se trabalhadores assalariados. Autoridades coloniais podem ter tido um "compromisso em ver os africanos libertados... como potenciais trabalhadores em plantations" ${ }^{28}$, mas elas não foram maciçamente bem sucedidas nisso.

Um ajuste de contas aproximativo é possível agora. Se assumirmos que $15 \%$ (27.000) morreram durante o primeiro ano após o desembarque, que $4 \%$ (7.000) se tornaram escravos no sentido pleno da palavra e que $27 \%$ (48.000) viraram trabalhadores assalariados, o que pode ser pensado quanto à maioria remanescente de 54\% (95.600)? O resultado, para a maioria, conforme apontado quanto às Bahamas por Rosanne Adderley, foi o assentamento em aldeias específicas, inicialmente com suporte governamental, mas no fim das contas em um ambiente no qual a agricultura ou a pesca autossuficientes foram muito mais importantes que o trabalho assalariado ${ }^{29}$. Mas, acima de tudo, o reassentamento em aldeias é o padrão associado a Serra Leoa. A Tabela 3 demonstra que a colônia recebeu uma entrada líquida de 78.000 africanos livres, embora, considerando a mortalidade subsequente à chegada, as posteriores transferências para o Caribe e as menos importantes repatriações para a área Ioruba, entre outros movimentos, o total provavelmente se aproximou mais de 50.000. Isso significou, de longe, uma proporção de africanos livres na população anfitriã maior que a de qualquer outra região que recebeu recapturados a partir de 1808 .

Isso direciona a atenção para o segundo elemento que se destaca nessa síntese. Os povoadores gravitaram ao redor de ou criaram aldeias nas quais as pessoas eram mais parecidas com eles mesmos. Esse padrão foi

27 MAMIGONIAN. To be a liberated African in Brazil, op . cit.

28 ADDERLEY. "New Negroes From Africa”, op. cit., p. 65.

29 Ibidem, p. 23-62. 
facilitado pelo fato de as aldeias novas terem frequentemente resultado de chegadas súbitas de pessoas que haviam atravessado o Atlântico no mesmo navio negreiro, assim como do fato de que as embarcações escravistas capturadas raramente tinham embarcado escravos em mais de um local. Sabemos que oitenta por cento dos navios negreiros que desembarcaram recapturados em Serra Leoa tinham chegado ali por volta de 1845, e segue-se da Tabela 2 que três quintos dos assentados devem ter sido, ou principalmente Ioruba, ou primordialmente Igbo. É realmente surpreendente que, embora Serra Leoa tenha recebido dos africanistas uma atenção que não guarda proporções com seu tamanho e população, quase ninguém tenha estudado os padrões cambiantes das identidades no interior dessas comunidades. De forma análoga, os estudiosos da diáspora geralmente optaram por trabalhar com as manifestações americanas, e não africanas, das mudanças identitárias associadas à migração. A diáspora dos africanos livres fornece uma oportunidade única para perseguir deslocamentos identitários nos dois lados do Atlântico, começando com a mesma amostra de base de migrantes.

Como exemplo, devemos notar que os Ewe-Fon, assim como vários subgrupos Ioruba e Igbo, formaram comunidades a milhares de milhas de casa tanto no Velho quanto no Novo Mundo. Pareceria, no entanto, que uma substituição ou ajustamento da identidade original ao novo ambiente aconteceu muito rapidamente nos dois exemplos. Durante a década de 1840, quando as chegadas de africanos livres em Serra Leoa estavam no topo, Sigismund Koelle realizou um bem conhecido inquérito linguístico e étnico da colônia, tendo ilustrado a enorme multiplicidade de povos africanos que ali viviam. Hoje em dia, é difícil encontrar traços significativos até mesmo dos maiores grupos entre os que foram identificados por Koelle. Possivelmente, a única exceção é a de um pequeno grupo de Okus ("Aku” é uma saudação Ioruba), o que não surpreende, em vista da extraordinária resiliência cultural da diáspora Ioruba. Eles são os muçulmanos Krio, que se identificam como descendentes dos Ioruba e que vivem em comunidades espalhadas pelas áreas de Fula Town e da baía de Fourah na parte Leste de Freetown, assim como na aldeia de Aberdeen, no Oeste ${ }^{30}$. Os africanos livres e seus descendentes se mesclaram maciçamente às sociedades Kissi, Mandinga, Susu, Mende e Temne. Estes últimos grupos dominam esma-

30 Comunicação pessoal de Phil Misevich, 4 de abril de 2008. 
gadoramente a região hoje em dia, assim como o faziam antes da chegada dos forasteiros. A herança identitária do grupo Rada em Trinidad, ou a dos Ioruba que criaram sua própria aldeia perto de Mobile logo que pisaram em terra saindo do último navio negreiro chegado aos Estados Unidos não é provavelmente muito diversa da de qualquer outro grupo de migrantes recapturados que se estabeleceu em Freetown e arredores ${ }^{31}$. Décadas depois do ensaio original de Mintz e Price, isso é mais ou menos esperado, mas já é tempo de reconhecer que esses padrões não ficaram limitados às Américas.

Em resumo, a importância do que está descrito aqui vai além do segmento dos africanos livres da diáspora africana. Pelo menos para $\mathrm{o}$ intervalo anterior a 1845, as origens do grupo dos africanos libertados são, em seu conjunto, muito mais restritas que as origens dos escravos traficados como um todo. Uma característica distintiva adicional do grupo dos africanos livres é o fato de sabermos muito mais sobre os detalhes pessoais e sobre as comunidades que estabeleceram após suas experiências nos navios negreiros. Quanto a bem mais que metade do grupo, também sabemos a destinação final da embarcação na qual eles foram encontrados. Por fim, é importante lembrar que os africanos da maioria dos navios negreiros capturados tinham grande probabilidade de ser mantidos juntos após a libertação. Frequentemente terminavam reassentados em um punhado de aldeias vizinhas (ou mesmo em uma única aldeia). Em contraste, os escravos de um navio negreiro que completasse sem interrupção sua jornada até as áreas de plantation nas Américas eram normalmente dispersados por várias plantations e, em muitos casos, sujeitados a longas jornadas adicionais por um dos muitos ramos do tráfico de escravos intra-americano. Devem ter sido estabelecidas e mantidas muito mais conexões entre companheiros de embarcação no interior desse grupo de migrantes forçados que no tráfico transatlântico de escravos em seu conjunto. É óbvia a possibilidade de usar esse grupo como substituto ou amostra dos africanos não interceptados na migração forçada em massa. Isso significa, essencialmente, uma defesa de que os africanos livres devem ser deslocados para o centro dos estudos da

31 DIOUF, Sylviane. Dreams of Africa, op. cit., e ADDERLEY. "New Negroes From Africa”, op. cit., p. 113-17. Ver a viagem $36990 \mathrm{em} \mathrm{http://slavevoyages.org/tast/database/search.faces?} \mathrm{yearFrom}$ $=1514 \&$ yearTo=1866\&voyageid=36990. A herança Ioruba e Ewe-Fon na Bahia é indubitavelmente mais forte que a dos grupos mencionados aqui, mas, de fato, o contato entre as comunidades de ambos os lados do Atlântico - a Bahia e Porto Novo, digamos - nunca foi realmente interrompido. 
diáspora, saindo de sua periferia, onde, apesar de estudos recentes de alta qualidade, sua análise tendeu a definhar.

O significado efetivo das experiências dos africanos livres, contudo, está além do fato de serem potencialmente representativos quanto à dinâmica das comunidades na diáspora para as quais menos informação sobreviveu, ou de gerarem insights a seu respeito. Os registros realmente extraordinários que suas vidas criaram nos permitem reexaminar tanto os arranjos de trabalho que se configuraram no mundo atlântico com o fim da escravidão, quanto a produtividade do conceito de "graus de liberdade" para processos associados a essa derrocada. Os africanos libertados podiam ser encontrados em todas as categorias definidas pelos historiadores dentro do espectro que ia da completa escravidão, em um extremo, até a liberdade pessoal plena e sem compulsoriedade, no outro extremo. O relativamente pequeno grupo que alcançou a liberdade pessoal pode ser exemplificado com a congolesa Catherine Zimmerman Mulgrave, com o Ioruba Samuel Ajayi Crowther, ou ainda com o Nupe John Ezzidio, que se tornou um dos mercadores mais ricos de Serra Leoa e um dos membros do Conselho Legislativo da Colônia ${ }^{32}$. Os historiadores interessados nesse assunto quase sempre começaram escolhendo uma sociedade na qual a escravidão estava abolida, para em seguida tentarem seguir o rastro de indivíduos que passaram do estatuto de escravos para alguma forma de estatuto não cativo após a abolição ${ }^{33}$. Os 177.000 africanos libertados permitem uma abordagem diferente. Esses indivíduos foram introduzidos em praticamente todas as sociedades escravistas das Américas entre 1808 e 1866 - e muitos viveram não apenas mais que o tráfico de escravos, mas também além da abolição da própria escravidão nas Américas. Há um importante livro esperando para ser escrito não apenas sobre as implicações culturais da diáspora, mas também sobre o real significado da liberdade para os cativos libertados de navios negreiros no Atlântico. No grupo dos africanos livres, deve ter sido

32 FYFE, Christopher. A History of Sierra Leone. Oxford, 1961, p. 231-32, 319-20 e Sierra Leone Studies. ASIEGBU. Slavery and the Politics of Liberation, op. cit., p. 29, identifica Ezzidio como Igbo. Para outras biografias de recapturados situados no termo "livre" do espectro em Serra Leoa, ver KOPYTOFF, Jean Herskovits. A Preface to Modern Nigeria: The Sierra Leoneans in Yoruba, 1830-1890. Madison, Wisc., 1965, p. 283-301.

33 Entre os melhores do gênero, COOPER, Frederick; HOLT, Thomas C.; SCOTT, Rebecca J. Beyond Slavery: Explorations of Race, Labor, and Citizenship in Postemancipation Societies. Chapel Hill, 2000. 
experimentado todo o espectro de condições inscritas no processo que levava uma pessoa do estatuto de escravo para o de não-escravo. Este ensaio não é mais que um ponto de partida da tentativa de tratar de suas experiências e das concepções mutáveis de raça e liberdade que essas experiências iluminam.

Recebido em 14/12/2009.

Aprovado em 15/03/2010. 